\title{
LXXVII. Process practised in the establishment of syoise sur seine to extract vinegar or acetic acid from wood
}

\section{M.P.L. Dupuytren}

To cite this article: M.P.L. Dupuytren (1818) LXXVII. Process practised in the establishment of syoise sur seine to extract vinegar or acetic acid from wood, Philosophical Magazine Series 1, 51:242, 439-442, DOI: $10.1080 / 14786441808637585$

To link to this article: http://dx.doi.org/10.1080/14786441808637585

曲 Published online: 27 Jul 2009.

Submit your article to this journal $\pi$

Џll Article views: 2

Q View related articles $₫$ 
From the above expriments, we see that the same hody may be made to produce either positive or negative electricity at pleasure; and that metallic bodies, like vitreons and resinous ones, will by similar treatment, like them, produce similar states of electricity.

From which I think it is but fair to conclude, that the classing of hodies into electrics and nom-electrics, as well as into positive and negative electrics, is founded in error, and at variance with experiments.

P.S.-The silk which I used was wrapped several times round a thin board about one font three inches long, and five inches swide, with a handle similar to a battledore.

Dorsst-treet, June 14, 1818.

$$
\text { I am, sir, yours, \&e. }
$$

\section{J. TATUa:}

LXXVII. Process practised in the Establishment of Syoise sur Seine to extract Vinestar or Acctic Acia' from Word. By M. P. L. Dupuxtren

$A_{\mathrm{T}}$ one end of a large building calculater for the purpose, are four furnaces, adapted to receive large rotorts, the lower parts of which are made in cast iron, and the rest in strong iron plates: at a small distance from the bottom of these retorts is the openjug of a copper pipe of three inches diameter, which rises through the metal of the retort, and widens like a tumel at the upper end; a copper eylinder eight or nine inches wide, and eighteen or twenty long, is fixed to this tumel, passing out of the building, is bent downwards, and is plunged into a large tub full of water, which is constantly renewed: from this it discharges itsclif into a condenser, to which are adapted on one side a small tock to carry off liquids, and on the other a clinder of about the same bore as the one mentioned above, and which rises vertically, then turns down and enters into the building, where it is again bent, and opens at the hearth of the furnace.

This apryaratus being arrangct, the retorts are filled with pieces of wood which have been cut a year, and which must be chosen straight and long, and about as large as the wrist: these pieces are arranged in the retort with order. When the retort is full, it is covered with its lid, which is fastened on by means of screws; it is then luted' carefully with clay, and by means of a crane two men raise it up and place it in its furnace: over this is put a covering of masonry of considerable weight; the cyfinder is fitted to the retort, and the fre is lighted.

* From the Journal de Pharmacie. 
The water which is in the wood soon dissipates, and the carbonization begins. Then there is disengaged a good deal of carbonic acid; acetic acid combined with water; carbonated hydrogen; and an oily matter similar to tar, with perhaps a simall portion of carbonic acid gas.

From part of the retort in which the decomposition is made, all these matters are forced to pass through the entire mass of wood to get to the opening of the pipe before mentioned, which is purposely placed at the inferior extremity; by this pipe they enter into the copper cylinder which conveys them to the condenser; there almost all that is water, the acetic acid and oily matter become condensed, and run off through the little cock; while all the carbonic acipl, the carbonnted hydrogen gas, carbonic acid gas, which also carry with them a small quantity of the other products, rise up by the other cylinder, and go into the fire, where they serve as fuel.

When this operation has continued five hours, these inflammable vapours are directed, by me: $n$; of a cock, under the fire of another retort, just lighted; the heat of the first fumace, and that which escapes from the wood during its decomposition, being sufficient to complete the carbonization of all which is contained in it, without the aid of the combustion of the gas. It is not necessary even to wait till the evaporation of these vapours has ceased, before the tube is removed from the ash-pit of the first furnace, because the charcoal wonld be too weal.

As soon as the neighbouring retort begins to give ont its gaseous products, and can do without further assistance, the pipe is removed from the ach-pit, and the remaining gas which comes out is ignited, in order to prevent the disagreeable sniell arising from it. The flame thus produced is as large as the pipe, rises many feet above, the pipe, and lasts about half an hour. The moment the retort is removed, it is rephaced by another, and the same process is observed as with the former.

Caution however is required in this process; for the moment the retort is taken out of the furnace, the copper cylinder is filled with inflammable gas: if it is joined and lated immediately to that which succeeds it, the gas will mix with the air contained in it, and the very smaliest spark that could pessibly penetrate the fissures of the retort would occasion an explosion; for which reason the apparatus is never to be luted till the very instant of the appearance of the empyreumatic vapour.

The retorts are from about seventy-two to a hundred cubic feet in capacity. They contain one and a half to two loads of wood, which, when it is well chosen and of a good quality, will yield twenty-eight per cent. of charcoal, and yield two hundred 
and forty to three hundred litres of pyroligneous arid, containing one-twelfth of tar.

The charcoal retains the form of the wood; it is intermixed only with a small quantity of dust which proceeds from the bark ; it possesses all the qualities of good charcoal, but its combustion is more rapid and more brilliant, and less. is requited for raising liquors to boiling heat. If exposed in contact with the air, it gains ten per cent. in weights.

The most satisfactory results are obtained from hard woods; but white woods are rejected : it takes five or six hours to char the wond, and seven hours to cool the charcoal.

When the retort is taken out, the pyroligneous acid is a reddish, semi-transparent liquid, and of a strong einpyreumatic acid taste and smell; every hundred parts will saturate as nuch subcarbonate of alkali as seven and a half to nine and a half of sul. phuric acid will concentrate.

The liquid flows from the condenser in a continual stream, of the size of a goose quill, and is conducted into a large wooden cask placed in a cellar, where, in cooling, it deposits the greater part of its tar; hence it jasses into another eask, where it remains in store.

It is preferable in this state to vinegar for all kinds of dyeing and printing on linen; it possesses an oil which is an excellent mordant for linen and colton, and prints with a more brilliant, durable, and fine colonr. It likewise serses to give a rose-colour to woods, feathers, and straw, \&c.

In order to separate the aeid from the empyreumatic oil, which colours and changes its nature, it is rum into a large iron boiler, where as much subcarbonate of lime is added as it can decompose when colld. When arrived at this point, a cestair. cuantity of the tar which floats on the surface is taken off with at skimmer, and by means of a pump the liquor is raised up in a cauldron, where it is then boiled. The saturation is then continued with quick-line, and decomposes the agetate of alkali which remains in dissolution; and the sulphate of lime which precipitates, carries with it a fresh quantity of tar.

The deposit being accomplished, the lifuror is passed into another cauldron, and there it is concentrated by a slight boiling till a thin shin arises; then it is put into wooden tubs, where in cooling it becomes solit.

The prodnce thus obtained is extremely inpure and black, in consequence of its retaining some portion of oily matter. This foreign substance resists repeated crystallization, and cannot be taken away except by melting. These impure crystals are therefore put into a cast-iron cauluron, where they undergo the 
aqueous fusion; all the water that they contain is evaporater; and when they are dry, the fire is increased till all the natter is in a burning fusion. It is then run into appropriate squares, in which it becomes solid.

In this state it is black like coal, but it easily dissolves in warm water; and this solution filtered and stirred with care gives crystals of acetate of alkali, which retain scarcely any of the empyreuma. It is then melted in a certain large puantity of water, and is decomposed by means of sulphuric acid of commerce ; it then gives out sulphate of alkali crystallized, and acetic acid, which only remains to be distilled to be obtained in perfect purity. The process may becarried on in large stone pitchers, called tourilles. While the burning fusion is going on, only a small quantity of acetate of alkali is decomposed, which depends probably on the presence of the oily matter.

This acetic acid, thus rectified, shows eleven degrees on the hydrometer of Baumé. It is to be preferred to distilled vinegar, as the latter is never so concentrated, and always retains some portion of vegetable matter which injures the beauty of the fabrics; besides which, for all preparations to be done with the acetic acid of wond, it does not require to be purified.

In order to concentrate this acid to a proper state for crystallization, it is sufficient to combine it with acetate of lime, and to decompose this salt slightly calcined, by concentrated sulphuric acid. At the instant of contact the reaction is extremely rapid, and the acetic acid is disengaged, giving up to the sulphate of lime all the superfluous water.

The waters from the first and second crystallization of the acetate of alkali are no longer susceptible of giving fresh crystals by evaporation. As that, no doubt, depends on the too great quantity of oily matter which is in it, it is probable that by calcining them alone, or with a mixture of charcoal powder, or perhaps by making them boil with charcoal, they might again acquire the properties of crystallization.

Being evaporated to dryness, they are mixed with tar, and then serve as fuel to heat the cauldrons. But as the cinders from them are not quite deprived of the acetate of alkali, they are passed through a reverberating furnace, washed in lye, and by the second crystallization the finest subcarbonate of alkali is olbtained. 